\title{
Thigh pyomyositis caused by group A streptococcus in an immunocompetent adult without any cause
}

\author{
Kensuke Minami $^{1,2}$, Tsuneaki Kenzaka ${ }^{1,3^{*}}$, Ayako Kumabe ${ }^{1}$ and Masami Matsumura ${ }^{1}$
}

\begin{abstract}
Background: Pyomyositis is typically caused by Staphylococcus aureus, and is rare in temperate climates, although its prevalence has been recently increasing. This infection often involves the thigh, and is associated with immunodeficiency.

Case presentation: We report the case of a healthy 20-year-old Japanese woman who experienced a fever and continuous pain for several days. She was admitted to our hospital and was diagnosed with pyomyositis after we discovered an abscess between the muscles of her dorsal distal left thigh using computed tomography. This is a rare case of thigh pyomyositis, as it was caused by group A streptococcus and occurred in an immunocompetent adult from a temperate climate.

Conclusions: Our review of the literature revealed that group A streptococcus pyomyositis typically occurs in temperate climates, among young adults without any underlying disease, and is associated with a poorer prognosis, compared to general pyomyositis. We suggest that pyomyositis should be considered when immunocompetent adults present with apparently idiopathic inflammatory muscle lesions.
\end{abstract}

Keywords: Pyomyositis, Group A streptococcus, Immunocompetent adult

\section{Background}

Pyomyositis is a bacterial infection of the skeletal muscle that is most commonly caused by Staphylococcus aureus (S. aureus; $90 \%$ of tropical cases and $75 \%$ of temperate cases) [1], although it is relatively rare in temperate climates. Another $1-5 \%$ of cases involve group A streptococcus, and other rare cases may involve streptococcus (groups B, C, and G), pneumococcus, Neisseria spp., Haemophilus spp., Aeromonas spp., Serratia spp., Yersinia spp., Pseudomonas spp., Klebsiella spp., and Escherichia spp. [1]. The development of pyomyositis is typically associated with immune-related conditions (e.g., diabetes mellitus, the use of corticosteroids, human immunodeficiency virus (HIV) infection, acquired immune deficiency

\footnotetext{
*Correspondence: smile.kenzaka@jichi.ac.jp

${ }^{3}$ Division of Community Medicine and Career Development, Kobe University Graduate School of Medicine, 2-1-5 Arata-cho, Hyogo-ku, Kobe, Hyogo 652-0032, Japan

Full list of author information is available at the end of the article
}

syndrome (AIDS), and malignancies), and most commonly affects the muscles of the lower extremities (i.e., the thighs and calves) [2]. Among immunocompetent patients, pyomyositis is typically accompanied by a history of a traffic accident [3] or vigorous exercise [4]. Furthermore, pyomyositis caused by group A streptococcus (GAS) is a known complication of chicken pox among children [5]. Therefore, we report a case of apparently idiopathic thigh pyomyositis that was caused by GAS in an immunocompetent adult.

\section{Case presentation}

A 20-year-old Japanese woman was working in a restaurant and experienced discomfort in her left thigh on the seventh day before her hospital admission. On the next day, she felt pain in the same area while walking, and subsequently consulted a physician, who prescribed an antiphlogistic sedative patch on the fifth day before her admission. On the third day before her admission, she 
developed a fever $\left(38{ }^{\circ} \mathrm{C}\right)$ and subsequently consulted another physician, who prescribed an antipyretic drug. However, she continued to experience fever and pain in her left thigh flexor during rest. Therefore, she consulted another physician and was admitted to our hospital, where she was prescribed a single dose of acetaminophen (400 mg). She did not have a history of domestic or overseas travel, participation in outdoor activities, or trauma.

Upon admission, she had a blood pressure of $110 / 63 \mathrm{mmHg}$, a pulse of 107 beats/min, a respiratory rate of 16 breaths $/ \mathrm{min}$, and a temperature of $38.9^{\circ} \mathrm{C}$. Her left thigh flexor appeared slightly red, with mild swelling, warmth, and pain. However, her head, lungs, heart, abdomen, and back did not exhibit redness or swelling. Her white blood cell count was 12,100 cells $/ \mathrm{mm}^{3}$, her hemoglobin level was $10.8 \mathrm{~g} / \mathrm{dL}$, and her C-reactive protein level was $24.11 \mathrm{mg} / \mathrm{dL}$. Her liver and renal functions were normal, and the HIV antibody/p24 antigen test (fourth generation) provided negative results. However, enhanced computed tomography (CT) revealed fluid between the dorsal distal muscles of her left thigh and an enhanced margin of fluid (Fig. 1), which we diagnosed as an abscess. There were no other abscess-like formations outside of her lower extremities.

An incision was made in her left thigh on the day of admission, the abscess was continuously drained, and we treated her using ampicillin/sulbactam (four doses per day, up to $12 \mathrm{~g}$ daily). Two sets of blood cultures provided negative results; however, a culture of a fasciotomy specimen from the abscess revealed positive results for GAS. Definitive identification of the GAS isolate was performed using the rapid streptococcus test (Rapid ID32 STREP; bioMerieux SA, Marcy l'Etoile, France). Therefore, we changed the patient's treatment to penicillin $G$ (24 million units per day via continuous infusion) on day 5. However, drug eruption in response to the penicillin G was suspected on day 12, and we changed the antibiotic to clindamycin on day $13(2700 \mathrm{mg}$ in three doses per day). We stopped the continuous drainage on day 15 , and switched the treatment to oral clindamycin on day 16 (600 mg three times per day). The patient was discharged after 17 days in the hospital, and her antibiotic treatment lasted 4 weeks. We did not observe any side effects that were related to the clindamycin treatment. The patient has remained in good health during the 1-year follow-up after her discharge from the hospital.

\section{Conclusions}

We encountered a rare and apparently idiopathic case of non-tropical pyomyositis that was caused by GAS in a healthy young Japanese woman. In this context, pyomyositis is rare in temperate climates, although it has

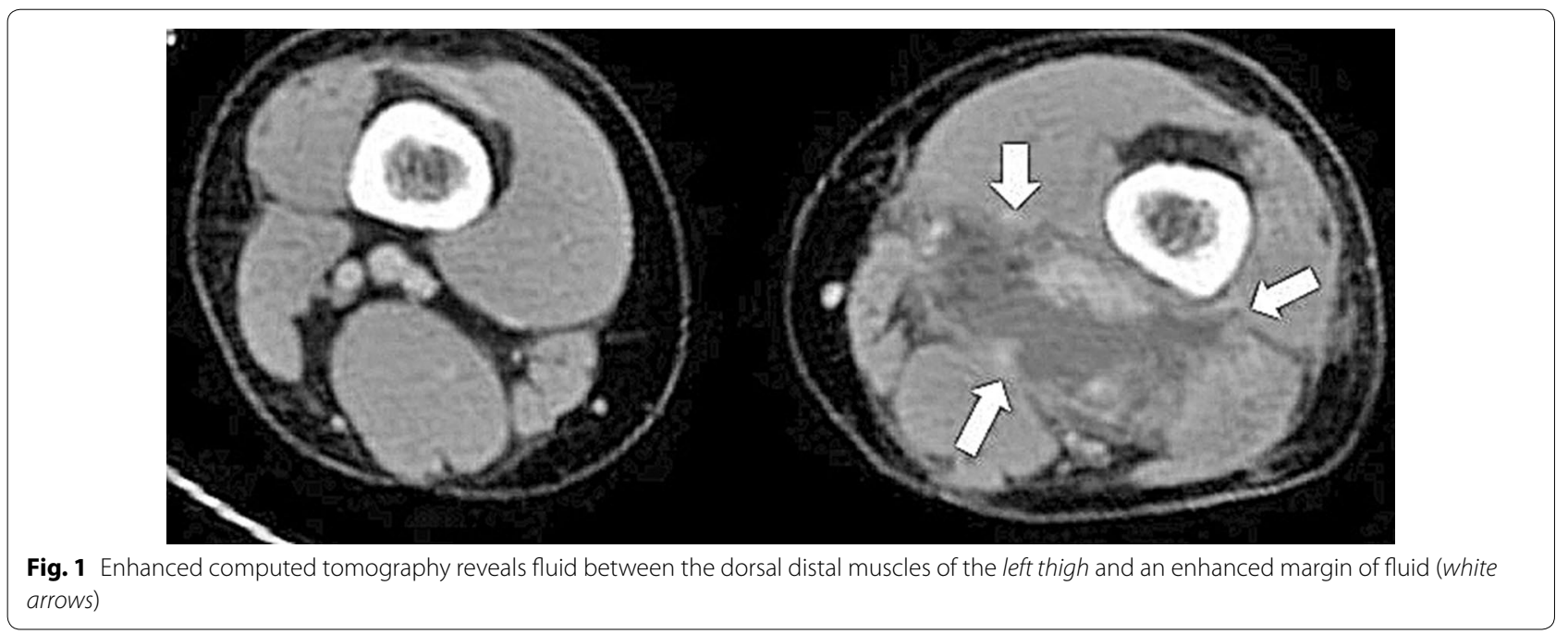


recently become more frequent in these climates [6]. The clinical features of temperate and tropical cases of pyomyositis are summarized in Table 1.

The clinical features of the reported GAS pyomyositis cases are summarized in Table 2 [5, 9-27]. Many of these cases occurred in temperate climates $(20 / 24$, $83.3 \%$ ), and most patients were children or young adults, with relatively few middle-aged patients (mean age, $30.3 \pm 21.0$ years). However, the 20 cases of GAS pyomyositis from temperate climates exhibited a mean age of $31.5 \pm 22.3$ years, and only included six pediatric cases, which differs from the general characteristics of tropical pyomyositis. Furthermore, GAS infection is a known complication of chicken pox in children [5], although only 1 of the 6 pediatric cases was GAS-positive. Although pyomyositis typically occurs in the lower extremities $(9 / 24,37.5 \%)$ [5, 9-27], other muscle groups can be involved, such as the iliac [10], psoas [11, 17], iliopsoas [11], trunk [5], neck [13, $18,26,27]$, and upper extremity muscles $[14,16,19$, $22,25]$. Involvement of multiple muscle groups is also common (9/24, 37.5\%). Interestingly, cases of GAS pyomyositis typically resemble general pyomyositis [28], although many cases are apparently idiopathic, which is more similar to cases of tropical pyomyositis [2]. Positive blood cultures were observed in 9 of the 24 temperate cases (37.5\%), approximately $60 \%$ $(14 / 24)$ of the cases involved surgical drainage (which was performed via fasciotomy), and no cases required amputation. The mortality rate was $12.5 \%(3 / 24)$, and four cases involved an intensive care unit stay, which would indicate that the temperate cases were more severe than general pyomyositis $[6,9]$. Thus, GAS pyomyositis typically occurs in temperate climates, among young adults without underlying disease, and is associated with a poorer prognosis, compared to general pyomyositis. The reasons for these observations are unclear, although Mandell, Douglas, and Bennett's Principles and Practice of Infectious Diseases [29] indicates that most GAS pyomyositis cases occur spontaneously or after blunt non-penetrating trauma, and the bacteria are most likely hematogenously translocated from the throat to the deep tissues. In addition, GAS is the most common cause of bacterial pharyngitis among children and young adults [29]. Furthermore, children and young adults are often highly active and may readily experience blunt non-penetrating trauma. Therefore, we hypothesize that the clinical features of GAS pyomyositis may be related to these factors.

It is difficult to diagnose pyomyositis, as there are no specific symptoms, and the only early symptoms are minor pain and swelling. Therefore, patients are often slow to consult with a physician, and the diagnosis is often delayed by 2-3 weeks [1]. When the diagnosis is delayed, death can be caused by septic complications, which include toxic shock syndrome [9]. In the present case, the patient exhibited minor swelling, redness, and warmth in her thigh, and we were able to rapidly diagnose pyomyositis based on our physical findings and the CT results. This rapid diagnosis allowed us to quickly start antibiotic treatment and drainage, which are both critical for treating pyomyositis (except during the early stage) [30].

We reported a rare case of apparently idiopathic thigh pyomyositis that was caused by GAS in an immunocompetent adult. Furthermore, our review of the literature revealed that GAS pyomyositis typically occurs in temperate climates, among young adults without any underlying disease, and is associated with a poorer prognosis, compared to general pyomyositis. Therefore, pyomyositis should be considered when a patient presents with inflammatory lesions in the thigh or other common

Table 1 The general clinical features of pyomyositis in temperate and tropical cases

\begin{tabular}{|c|c|c|}
\hline & Temperate cases & Tropical cases \\
\hline Ages $[1,2,7]$ & Adults (elderly) & Children ( $2-5$ years) and adults ( $35-40$ years) \\
\hline Underlying conditions $[2,8]$ & $\begin{array}{l}\text { Immunocompromised or serious underlying conditions, } \\
\text { such as HIV infection, diabetes mellitus, leukemia, chronic } \\
\text { renal failure, asplenia, scleroderma, rheumatoid arthritis, Felty's } \\
\text { syndrome, chemotherapy, or immunosuppressive treatment }\end{array}$ & Healthy \\
\hline Microbiology (S. aureus) [1] (\%) & $60-75$ & $>90$ \\
\hline Positive blood cultures [1] (\%) & $20-30$ & $5-10$ \\
\hline Mortality $[6,9](\%)$ & $6.0-9.4$ & $0.5-2.0$ \\
\hline
\end{tabular}




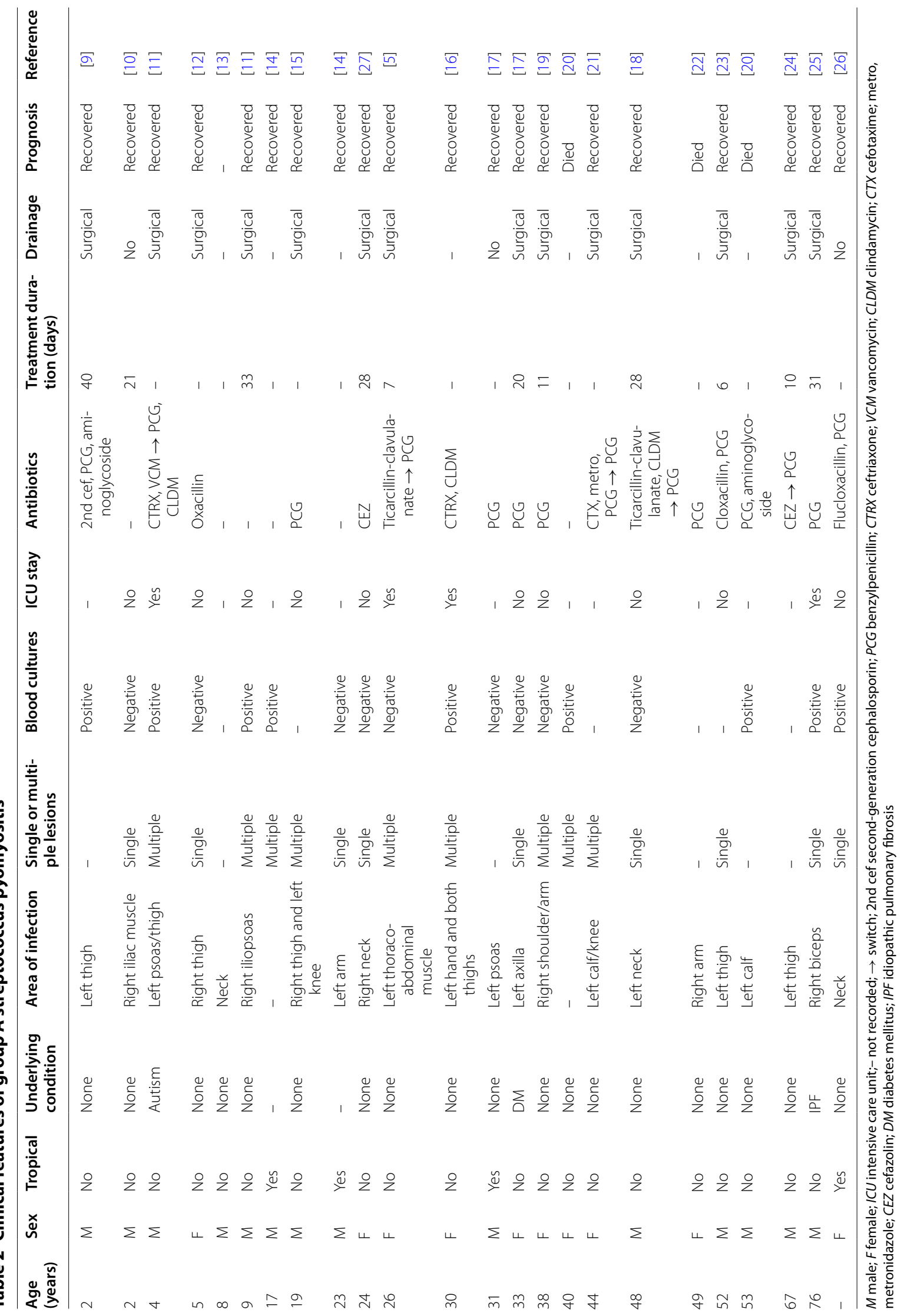


pyomyositis sites, even when the patient is not immunocompromised and does not exhibit the standard characteristics of pyomyositis.

\section{Abbreviations}

GAS: group A streptococcus; CT: computed tomography; HIV: human immunodeficiency virus; AIDS: acquired immune deficiency syndrome.

\section{Authors' contributions}

KM: Managing the patient, writing the manuscript, and revising the manuscript. TK: Writing, correcting, and revising the manuscript. AK: Management the patient and revising the manuscript. Masami Matsumura: Revising the manuscript and the figure. All authors read and approved the final manuscript.

\section{Author details}

${ }^{1}$ Division of General Internal Medicine, Jichi Medical University Hospital, Shimotsuke, Japan. ${ }^{2}$ Department of General Medicine, Toyooka Public Hospital, Toyooka, Japan. ${ }^{3}$ Division of Community Medicine and Career Development, Kobe University Graduate School of Medicine, 2-1-5 Arata-cho, Hyogo-ku, Kobe, Hyogo 652-0032, Japan.

\section{Acknowledgements}

None.

\section{Competing interests}

The authors declare that they have no competing interests.

\section{Availability of data and materials}

All data supporting our findings are contained within the manuscript.

\section{Consent for publication}

Written informed consent was obtained from the patient for publication of this Case Report and any accompanying images.

\section{Funding}

No funding was received for this report.

Received: 30 June 2016 Accepted: 16 December 2016

Published online: 07 January 2017

\section{References}

1. Chauhan S, Jain S, Varma S, Chauhan SS. Tropical pyomyositis (myositis tropicans): current perspective. Postgrad Med J. 2004;80:267-70.

2. Lopez-Rodriguez R, Campos-Franco J, Mallo-Gonzalez N, Alende-Sixto MR, Gonzalez-Quintela A. Sternocleidomastoid and pectoralis major pyomyositis in an immunocompetent patient. Orthopedics. 2008;31:1146.

3. Diamandakis V, Grose C. Bad consequences of bicycle accidents. Pyomyositis. Pediatr Infect Dis J. 1994;13:422-5.

4. Jayoussi R, Bialik V, Eyal A, Shehadeh N, Etzioni A. Pyomyositis caused by vigorous exercise in a boy. Acta Paediatr. 1995;84:226-7.

5. Cherry C, Wiggins K, Mijch A, Ostergaard L. Non-tropical thoraco-abdominal pyomyositis caused by group A streptococcus in an immunocompetent adult. Scand J Infect Dis. 2001;33:854-6.

6. Drosos G. Pyomyositis. A literature review. Acta Orthop Belg. 2005;71:9-16.

7. Bickels J, Ben-Sira L, Kessler A, Wientroub S. Primary pyomyositis. J Bone Joint Surg Am. 2002;84A:2277-86.

8. Christin L, Sarosi GA. Pyomyositis in North America: case reports and review. Clin Infect Dis. 1992;15:668-77.

9. Ali I, Rashdan I. Pyomyositis: a case report and literature review. Hosp Physician. 1999:35:39-42.

10. Ceulemans R, Clybouw A, De Schepper AM. Rapidly progressive pyomyositis. J Belge Radiol. 1995;78:226.
11. Kern L, Rassbach C, Ottolini M. Streptococcal pyomyositis of the psoas: case reports and review. Pediatr Emerg Care. 2006;22:250-3.

12. Cowan MR, Primm PA, Scott SM, Abramo TJ, Wiebe RA. Serious group A beta-hemolytic streptococcal infections complicating varicella. Ann Emerg Med. 1994;23:818-22.

13. Pannaraj PS, Hulten KG, Gonzalez BE, Mason EO Jr, Kaplan SL. Infective pyomyositis and myositis in children in the era of community-acquired, methicillin-resistant Staphylococcus aureus infection. Clin Infect Dis. 2006:43:953-60.

14. Brown JD, Wheeler B. Pyomyositis. Report of 18 cases in Hawaii. Arch Intern Med. 1984;144:1749-51.

15. Farrag N, Kavanagh TG, Chin T. Pyomyositis - an under-reported disease in temperate climates. J Infect. 1988;17:259-63.

16. Feigenberg T, Sela HY, Applbaum YH, Mankuta D. Puerperal widespread pyomyositis after group A streptococcal toxic shock syndrome. Isr Med Assoc J. 2008;10:483-4.

17. Skoutelis A, Andonopoulos A, Panagiotopoulos E, Bassaris H. Non-tropical pyomyositis in adults: report of four cases and literature review. Eur J Clin Microbiol Infect Dis. 1993;12:769-72.

18. Gosnell EJ, Anwar B, Varadarajan V, Freeman S. Sternocleidomastoid pyomyositis. Eur Ann Otorhinolaryngol Head Neck Dis. 2016;133:273-5.

19. Andrew JG, Czyz WM. Pyomyositis presenting as septic arthritis. A report of 2 cases. Acta Orthop Scand. 1988:59:587-8.

20. Adams EM, Gudmundsson S, Yocum DE, Haselby RC, Craig WA, Sundstrom WR. Streptococcal myositis. Arch Intern Med. 1985;145:1020-3.

21. Lawrentschuk N, Falkenberg MP, Pirpiris M. Primary bacterial pyomyositis associated with septic arthritis caused by Streptococcus pyogenes: a case report. Am J Orthop (Belle Mead NJ). 2003;32:148-50.

22. Jorup-Ronstrom C, Hofling M, Lundberg C, Holm S. Streptococcal toxic shock syndrome in a postpartum woman. Case report and review of the literature. Infection. 1996;24:164-7.

23. Mattingly PC, Mowat AG. Streptococcal pyomyositis following a sore throat. Rheumatol Rehabil. 1981:20:151-2.

24. Unger MJ, Van Winkle GN, Ness-Wenum S. Pyomyositis secondary to group A beta hemolytic streptococcus. Wis Med J. 1991;90:465-7.

25. Doebbeling BN, Wenzel RP. Spontaneous streptococcal gangrenous myositis: survival with early debridement. South Med J. 1989;82:900-2.

26. Collier S, Vig N, Collier J. Two cases of tropical pyomyositis of the sternocleidomastoid muscle occurring in the UK. Br J Oral Maxillofac Surg. 2010;48:216-7.

27. Martinez-Balzano C, Frechette V. Bacterial pyomyositis in a patient with sickle cell trait and pityriasis amiantacea. QJM. 2014;107:1035-7.

28. Crum NF. Bacterial pyomyositis in the United States. Am J Med. 2004;117:420-8.

29. Bennett JE, Dolin R, Blaser MJ. Mandell, Douglas, and Bennett's principles and practice of infectious diseases. 8th ed. Philadelphia: Elsevier; 2014. p. 2285-99.

30. Hossain A, Reis ED, Soundararajan K, Kerstein MD, Hollier LH. Nontropical pyomyositis: analysis of eight patients in an urban center. Am Surg. 2000;66:1064-6.

\section{Submit your next manuscript to BioMed Central} and we will help you at every step:

- We accept pre-submission inquiries

- Our selector tool helps you to find the most relevant journal

- We provide round the clock customer support

- Convenient online submission

- Thorough peer review

- Inclusion in PubMed and all major indexing services

- Maximum visibility for your research

Submit your manuscript at www.biomedcentral.com/submit 